\title{
Screening of the mental state of the over-75s in the community: what are GPs doing?
}

\author{
D. M. MACKENZIE, Registrar, Royal Edinburgh Hospital, Morningside Terrace, \\ Edinburgh EH10 5HF
}

The new general practitioners' contract requires the primary health care team to perform a yearly assessment of their patients of 75 and over. This includes an assessment of the 'mental condition'. In a list size of 2,000, typically 130 fall within this age group. Screening does not have to be carried out by the doctor and as $90 \%$ are already seen at least once a year, there is scope for opportunistic screening. Nonetheless, screening increases the general practitioner's workload and while it improves the morale of elderly people, it may have little impact on medical and functional problems.

Five to eight per cent of those aged over 65 have moderate to severe dementia, rising to $20-25 \%$ aged 80 . Twenty to twenty-five per cent of over $65 \mathrm{~s}$ may suffer from an affective disorder or neurotic illness.

This study looks at how GPs screen the mental condition of their patients of 75 and over.

\section{The study}

Two hundred Edinburgh GPs were sent postal questionnaires shortly after the implementation of the new general practice contract. The sample was a cross-sectional cohort selected randomly from a list of all general practitioners in the area.

\section{Findings}

Of the 200 questionnaires, 127 were returned completed. Of ten randomly selected non-responders: six said they were too busy to reply; two did not remember receiving it; one had recently retired and one said he received too many such questionnaires.

Where there is no obvious sign of confusion, 78 $(61 \%)$ would not routinely screen for cognitive impairment. Of the 49 who would screen, 48 specified which questions they ask. Eighteen use a standard test such as the mental status questionnaire (MSQ) or abbreviated mental test (AMT). Indeed, 12 use the former and two use the latter. Others use shortened versions of these, sometimes with other questions of their own (see Table I). In 36 the total number of questions asked could be counted. Of the half who were not using a standardised test, only two were asking 10 or more questions.
TABLE I

Questions used by 48 GPs to screen for cognitive impairment

\begin{tabular}{llr}
\hline & $\begin{array}{c}\text { Content of } \\
\text { question }\end{array}$ & $\begin{array}{c}\text { Number of GPs } \\
\text { using question }\end{array}$ \\
\hline$+\quad$ Age & 19 \\
& Time & 7 \\
$+\quad$ Day of week & 6 \\
$+\quad$ Today's date & 20 \\
$*+\quad$ This month & 20 \\
$*+\quad$ Location of interview & 22 \\
$+\quad$ Town & 15 \\
$*$ & Recognition of 2 persons & 12 \\
$*+\quad$ Date of birth & 7 \\
$* \quad$ Address/Telephone No. & 24 \\
$* \quad$ Address for recall & 8 \\
$* \quad$ Dates of historic event & 2 \\
$* \quad$ Present Monarch/Prime Minister & 6 \\
$* \quad$ Previous Prime Minister & 26 \\
& Other arithmetic & 13 \\
& & 14 \\
\hline
\end{tabular}

*=AMT 1 point, + = MSQ 1 point.

Ninety-six $(76 \%)$ said they would not routinely screen for functional mental illness (e.g. anxiety or depression) where there is no obvious sign of it. Of the 31 who would screen, none use a standardised questionnaire. Twenty-nine described their key screening questions: four ask one question about current mood, nine add up to two supplementary questions, usually enquiring about appetite or sleep disturbance. Of those who ask further questions most are aimed at the so called 'biological' symptoms of depression (Table II).

Twenty-five $(20 \%)$ said they would routinely check for organic mental impairment but not for functional mental illness, while six $(5 \%)$ said they would routinely screen the latter but not the former. Seventy-seven $(61 \%)$ said they routinely inquire about alcohol consumption. Fifty-two (41\%) already use a standardised checklist for their yearly assessment. Thirty-seven have devised their own; ten did not specify which they were using; while five were using generally available questionnaires such as 
TABLE II

Most frequently asked questions to screen for functional mental illness (sample: 29 GPs)

\begin{tabular}{lc}
\hline $\begin{array}{l}\text { Content of } \\
\text { question }\end{array}$ & $\begin{array}{c}\text { Number of GPs } \\
\text { using questions }\end{array}$ \\
\hline Sleep & 20 \\
Mood & 20 \\
Appetite & 15 \\
Weight change & 2 \\
Hobbies/interests & 10 \\
Worries/anxiety & 6 \\
Concentration & 7 \\
Energy & 2 \\
\hline
\end{tabular}

the geriatric medicine over-75s assessment checklist. Mental state assessment on schedules reviewed by the author varied from ringing of two appropriate words to performing an MSQ (or equivalent) and recording recent life events along with weight, diet, mood and sleep status.

\section{Comment}

When questioned shortly after the implementation of the new GP contract, $61 \%$ of GPs said they would not routinely screen for cognitive impairment of their over-75s in the absence of overt signs and symptoms. This increased to $76 \%$ when only functional mental illness is considered. Of course, much information is already available to the GP without specific enquiry. The patient is likely to be well known to him/her; he/she has an opportunity to observe the mental state during the general assessment; relatives and other informants often volunteer mood and cognitive changes; while obvious evidence of a deteriorating mental state may be apparent in the home (e.g. untidiness in the previously houseproud). Nonetheless, patients rarely complain of symptoms of dementia as they attribute them to the effects of normal ageing. Similarly, partly because old age is associated with various losses, the elderly may not identify a depressive illness as an abnormal mood state. Although effective annual screening does reveal new cases of depression, dementia and heavy drinking, there is still no good evidence that routine screening is worthwhile. It is therefore not surprising that only very brief methods are being used. Indeed only $14 \%$ report routine use of standardised tests such as the mental status questionnaire (MSQ) or abbreviated mental test (AMT). No depression rating scales are in use. Although depression is more prevalent than dementia or problem drinking, it is the least likely to be screened. Problem drinking, the least prevalent, was the most frequently considered. Excessive alcohol intake in younger patients is a common cause of physical and social dysfunction. GPs are therefore anxious not to miss it but perhaps feel mental state changes in patients they generally see regularly are more easily identified.

GPs may also be concerned about finding the time to make a fuller assessment of the greater number of cases identified by more sensitive screening tests. However, to avoid missing potential morbidity, if other members of the primary health care team conduct initial screening with more detailed rating methods, the GP need only see those meriting further assessment. Professor Haines' team (lliffe et al, 1991) has shown that such detailed assessment, using the mini-mental state examination and a depression scale from the comprehensive and referral evaluation (CARE) can be administered by team members to effectively identify unrecognised illness.

If GPs are to be encouraged to use more resources to screen their over-75s, they need to be persuaded that it is worthwhile. There is therefore a need for prospective outcome studies of valid screening methods.

\section{Acknowledgements}

I am grateful to Drs A. Jacques, P. Morrison, I. Pullen and L.Whalley for their advice and the GPs for their time.

\section{Further reading}

BOND, J. (1987) Psychiatric illness in later life. International Journal of Geriatric Psychiatry, 2, 39-57.

HodKINSON, H. M. (1972) Evaluation of a mental test score for assessment of mental impairment in the elderly. Age and Ageing, 1, 233-238.

Iliffe, S., Haines, A., Gallivan, S. et al (1991) Assessment of elderly people in general practice. 1 . Social circumstances and mental state. British Journal of General Practice, 41, 9-12.

McEwan, R. T., DA vison, N., Forster, D. P. et al (1990) Screening elderly people in primary care: a randomised controlled trial. British Journal of General Practice, 40, 94-97.

WILSON, L. A. \& BRASs, W. (1973) Brief assessment of the mental state in domicilliary practice. The usefulness of the Mental Status Questionnaire. Age and Ageing, 2, 92-101. 